\title{
Quality Assurance of Egyptian Higher Education: A Policy Transfer Perspective
}

\author{
Farida Ibrahim Ramadan, Zuraidah Zaaba, Katsuhiro Umemoto \\ JAIST, Japan \\ \{s0960207, hjhzuraidah.hjzaaba,ume\}@jaist.ac.jp
}

\begin{abstract}
A higher education is considered the source of opportunities and prosperity in all countries all over the world; also it is vital for competitiveness in the increasingly globalizing knowledge society Egyptian higher education, at the beginning of the new millennium, faces unprecedented challenges: not only is the demand for access unstoppable, but also higher education (HE) is recognized as a key force for modernization and development. Discussions of policy diffusion and transfer have primarily focused on official actors, and networks of the political and economical sectors. Policy transfer in HE sector, especially quality assurance (QA) policy, in national departments and nongovernmental organizations, is a relatively neglected dimension. Accordingly, this paper addresses a brief history of $Q A$ and accreditation policy of HE in Egypt, which we divide simply into main distinct phases; the Quality Assurance and Accreditation (QAAP) Phase, and the Program of Continuous Improvement and Qualifying for Accreditation (PCIQA). We also address how the Egyptian QA and accreditation life cycle is developing from the policy transfer perspective. This cycle we divide into two main stages according to the process; the QA formulation and setting stage, and the implementation stage. In the last section of our paper, we present a theoretical actor model of QA policy transfer. Based on our suggested model, we argue that both the Egyptian policy-setting and formulation, and implementation stages of $Q A$ and accreditation policy are strongly influenced by several actors, channels, of transfer; global, international, regional, and national channels.
\end{abstract}

\section{Introduction}

Higher Education systems became more complex and were forced to become more flexible and adjustable to change, which was incompatible with centralized systems of detailed oversight and control. At the same time, are facing unprecedented challenges arising from the convergent impacts of globalization, the increasing importance of knowledge as a main driver of growth, and the information and communication revolution. One of the most effective responses to these challenges, especially in developing countries, is creating and/or evaluating QA and accreditation mechanisms. For example, Maringe [1] states that enhancing the quality of HE has become one of the most prominent conceptualizations of internationalization in HE.

\section{Globalization and QA of HE}

Cultural and economic globalization has ushered in a new era in HE. The policies supporting quasimarkets and commercial markets in $\mathrm{HE}$ are expressed globally in the World Trade Organization (WTO) negotiations in the General Agreement on Trade in Services (GATS). In 2005, WTO/GATS focused on liberalizing the regulatory conditions governing trade in services, including HE, in each nation.

Many scholars, Currie \& Newson 1998; Scott 1998, Walker \& Nixon 2004, have written on the impact of globalization on universities. It is not a surprise that globalization discourse has affected HE in every aspect: policy-making, governance, organization, and academic work and identity. As Torres and Morrow [2] claim, "perhaps no place has been more subject to these processes of internationalization and globalization than university".

Porter \& Vidovich [3] show a number of common themes in the reaction of HE policy to globalization, as follows:

- Significant per capita government budget reductions have been experienced in HE, with higher education institutions (HEIs) expected to do more with less.

- The significant push to diversify income by increasing nongovernmental resources from the private sector. Alternative sources include tuition/fee increases, the recruitment of overseas students paying full fees, competition for research grants and centers, etc.

- The increased commodification of knowledge as intellectual property has occurred, particularly with regard to connecting the intellectual work of universities with community, business, and government interests and priorities.

- Reorganization of HE has been promoted by national governments (or in some cases state/provincial governments), to relate it more closely to national economic agendas. This has usually involved the demise of binary systems, 
(in the UK, Australia, and New Zealand), institutional amalgamations, the re-organization of campuses, the dismissal of staff, and new accountability measures that have typically involved greater centralized control over outcomes at the same time that decisions over educational processes have been decentralized.

- "Ministerialization," or the increased power of politicians, and in parliamentary systems also of the executive, has characterized political processes during this period.

- The pressures for new forms of accountability have increased at all levels. These can be seen in performance indicators at the institutional level for reporting to government, and in performance review and assessment at the individual academic level in relation to both research and teaching.

- Discourses of managerialism have become pervasive, imported into education from the private sector via earlier general public sector reforms. These have involved a focus on outcomes instead of inputs, measures for quality control, a concern for efficiency, and a focus on service to clients.

- Concerns with social justice and equity issues in HE have been evident, and can be seen most clearly in expanding access to HE in terms of numbers of places, types of entry, and increasing diversity of modes of study. However, policy development has noticeably varied with the differing commitment of different governments and different institutional administrations.

- A preoccupation with HE finance issues has developed at national levels. This has led to considerable public debates about the appropriate balance of public versus private contribution to postsecondary education, and in particular the size of the student contribution in relation to government funding.

- An intensified public and political debate about the role of universities in contemporary society. Some of the debate has been about the nature and extent of autonomy of universities as institutions, how responsive they should be to governments, to student demand, to industry, or to professions.

- Quality movements in HE have been established by governments.

However, the responses to globalization in the context of QA of HE sector differ between countries. All these previous trends can be conceived as processes of policy transfer, policy learning or policy borrowing which occurs across nations.

\section{QA movement of $\mathrm{HE}$}

The philosophy of quality, QA, and total quality management is derived from industrial and commercial practice. By the 1980s, the quality idea was imported from its familiar settings, industrial and commercial, into the domain of HE. Therefore, the traditional concept of quality is associated with the notion of providing a product or service that is distinctive and special, and which confers status on the owner or user.

Over the last twenty years, a new paradigm of the function of $\mathrm{HE}$ has emerged. While HEIs still maintain their main role as the conscience of society, more pragmatic roles have been evolving over time, by which HE will be judged in terms of outputs and the contributions it makes to national development.

In the beginning, quality movements in HE were established by governments, intended to monitor or audit institutional processes and outcomes, and funding is increasingly tied to the results. Accreditation in HE is used at the beginning of the twentieth century, in the USA and the UK the medical professions started an accreditation process of their professional education, and it was disseminated to other professions.

The quality of HE commands priority attention from not only policy-makers, but also international agencies and researchers worldwide. There are many reasons for emphasis on quality in $\mathrm{HE}$ :

- The greater scale of the HE enterprise in 1990 compared with 1980;

- The increased range of educational attainment of students entering HE for the first time;

- The popularity of modular courses with students, and a consequent decline in the proportion of graduates with single honours degrees;

- The increasing importance of part-time courses and hence in the participation of older students.

It can be observed that one aspect of international turbulence has been the growth of QA mechanisms of HE. In the educational sector, the concept of quality assurance refers to "the intention and activities planned to assure quality" [4]. Parri [5] concluded that quality in the higher education sector may refer to exceptionality and excellence, zero errors, fitness for purpose, transformation and reshaping, threshold, or enhancement. Therefore, QA in HE should be comprehensive and examine inputs, processes, and outputs [6].

Moreover, QA should be viewed, in the context of a country's public policy, as providing suitable educational opportunities for its citizens. So, the connection between HE institutional purposes, government policies which have been established to enable these institutions to achieve their purposes, and procedures that document institutional performance are essential.

In the USA the idea of QA dates back to the formation of accrediting bodies. The oldest of the six regional accrediting associations were established in the late 1800 s, and in the 1980 s, quality issues began to be introduced and implemented in distinctive ways in U.S. HE. 
Hence, to achieve QA objectives, the highest level of management should establish a quality system with a structure for effective control, evaluation and improvement of service quality.

Moreover, Cheung [10] illustrates that a good QA system should be designed to reflect different stakeholder interests and ensure quality by the interplay of such interests. Therefore Cheung spots the common elements which are found in such a system:

- A collegial, rather than adversarial, approach based on trust;

- Clear criteria and procedures;

- Starting with self-evaluation;

- External peers;

- Evidence-based;

- No surprises, no element in a report should be withheld from the institution before it is finalised;

- Transparency, although it is a pity that publication of the accreditation report is neither a requirement, nor a practice, in many well-developed jurisdictions;

- Right of representation and appeal.

For example, in Europe, the Bologna process is probably the most visible multinational transformation in the world today, and has a quality assurance dimension discharged through such multinational organizations as the European Association for Quality Assurance in Higher Education.

The modern literature in HE quality shows some quality principles and practices that might be helpful in building up an internal quality system, especially in developing a quality culture such as; care for quality at various levels in institutions; international orientation; the operational quality concept and quality system should be embedded in the overall institutional strategy; closing feedback loops; distributed leadership at all levels in the organization; the quality culture should be based on a top-down and bottom-up approach; the involvement of students; and the use of external expertise.

Accreditation is considered the gateway to total quality, and to be a motivation for institutions to promote comprehensive educational processes and quality systems to raise the level of confidence in the institution and its graduates. In other words, the accreditation criteria require the institution to have effective QA systems that underpin the appropriate academic standards of its programmes and the high quality of learning opportunities.

The accreditation process determines whether an institution or a program meets quality criteria, and then certifies this to the public. So, accreditation is seen to be criterion-referenced, which compares the observed performance against preset standards which are usually determined by the academic agency, which is external to the educational institution itself, or determined by other professionals. Also accreditation may be performed at the institutional or program level, and its final outcome- whether the institution meets threshold quality standards- is always published; this publication is necessary for accreditation to perform its certification function.

\subsection{Policy transfer}

Transfer was a topic frequently addressed by some of the leading middle-to-late twentieth century comparativists, among them Brian Holmes and Edmund King, thus the foreign example helps to explain, to inform and to provide a basis for speculation, rather than forms of scientifically arrived-at prediction.

The policy transfer literature emphasizes understanding the process by which policies and practices move from exporter to importer jurisdictions, or the process by which knowledge of policies, administrative arrangements, institutions and ideas in one political setting, past or present, is used in the development of policies, administrative arrangements, institutions and ideas in another political setting [7]. Hence, this transfer has several objects; policies, institutions, ideologies or justifications, attitudes and ideas, and negative lessons [8].

Dolowitz and Marsh [9] emphasized that there are different degrees of transfer; straightforward copying of policy, legislation or techniques, as well as various forms of emulation, synthesis and hybridization, and inspiration. Educational transfer occurs through a variety of mechanisms, such as diffusion, imposition or lesson-drawing. It includes the ideational, covert, and implicit dissemination of ideas, concept and discourse, (soft transfer), explicit policy borrowing and lending, and the imposition of concrete models, structures or practices.

Based on both a literature review of globalization effects on the HE sector, and a policy transfer literature review, we can say that the QA and accreditation policy of HE could be transferred, as well as political knowledge/policy through different channels such as; global/international conferences or seminars, global/international networks, international agencies or authorities, international consultants, academic exchange, international research projects on QA and accreditation practices, international/national forums on QA, etc.

This paper is structured into five parts. The next section shows the paper's methodology and objectives. The third section provides a general overview of Egyptian QA and accreditation policy formulation and implementation. The fourth section suggests a discussion and analysis of the Egyptian QA and accreditation policy from the policy transfer 
perspective. The fifth and final section draws a general conclusion.

\section{Methodology and objectives}

This paper engages in an in-depth investigation of one of the strategic processes in Egypt, namely, the national higher education QA and accreditation system and process, to offer a better understanding. Therefore, our strategy in this paper is a case study of Egyptian QA and accreditation policy. Moreover, a literature review on policy transfer, globalization impacts, QA policy, and secondary data has been conducted to analyze Egyptian QA policy from the policy transfer perspective, based on using our suggested theoretical model of QA policy transfer.

Hence, our paper focuses on three main questions:

1- What are the main features of the Egyptian higher education QA and accreditation system?

2- How is the Egyptian QA and accreditation life cycle developing?

3- What channels have Egyptian QA and accreditation policy been influenced by, from the policy transfer perspective?

\section{The history of QA and accreditation policy of Egyptian HE}

Egyptian $\mathrm{HE}$, at the beginning of the new millennium, faces unprecedented challenges. It is struggling for survival against an onslaught of overwhelming political, social and economic problems, rapid urbanization, rampant population growth, inefficient allocation of resources, and economic dependency. Therefore, authorities recognized the need to establish a national quality assurance system. Moreover, the Egyptian government considered the QA and accreditation mechanisms as a gateway towards motivation for its HEIs to promote comprehensive educational processes, and a quality system to raise the level of confidence in the institutions and their graduates.

\subsection{Egyptian HE system}

Egypt has the largest education system in the Middle East and North Africa (MENA) region. Egyptian $\mathrm{HE}$ is central to economic and political development, and vital to competitiveness in an increasingly globalizing knowledge society; it consists of public universities and post-secondary technical/vocational institutes, in addition to private institutions.

Two parallel education systems exist in Egypt, the secular system and the religious, or Al-Azhar, system. The secular system consists of five Phases; pre-school education, primary education, preparatory education, secondary education, and post-secondary, including HE. Al-Azhar education system is supervised by the Supreme Council of the Al-Azhar Institution, and is independent from the Ministry of Education. But the Al-Azhar Institution itself is placed under government supervision, and its educational system is actually supervised by the Egyptian Prime Minister. Al-Azhar schools include primary, preparatory, secondary, and AlAzhar universities.

HE in Egypt can be categorized into the public HE sector, comprised of public universities and nonuniversity institutions, which is dominant and large, and the private $\mathrm{HE}$ sector, mainly comprised of a small number of private universities. In general, Egyptian $\mathrm{HE}$ is organized in three institutional models [11]:

- The universities: higher educational institutions organized into colleges (faculties);

- The four-to-six-year institutes: each institute offers programs in one of the major fields, such as engineering, computer science, agriculture, and so on. Some of these institutions were organized to become part of a university;

- The two-to-three-year institutes: they offer programs that lead to a diploma.

Three bodies are responsible for the governance and control of HE, the Ministry of Higher Education (MOHE), the Supreme Council of Universities (SCU), and the Central Administration of Al-Azhar Institutes. The MOHE has jurisdiction over HE through the supervision and coordination of all postsecondary education, planning, policy formulation, and quality control. The SCU forms planning committees for various educational sectors of the universities. Each committee consists of the deans of similar faculties. These committees are responsible for studying and investigating, for example, the educational plans of each university, the general strategy for scientific research, and determination of academic departments and specialized institutes [12].

With the beginning of the $21^{\text {st }}$ century, Egyptian HE aims at very critical and important goals; responding to the current and future needs of social development, job market, and production; producing graduates who have the characteristics required for the $21^{\text {st }}$ century as follows:

- Possessing on-going and self-learning skills;

- Reflecting an all-round personality that reflects scientific, technical, intellectual, and cultural knowledge and skills, and capable of sustainable development;

- Ability to utilize scientific research and to develop scientific competencies;

- Possessing effective communication skills; 
- Asserting self-confidence and demonstrating competitive capabilities;

- Ability to think critically and solve problems;

- Preserving cultural identity and national language;

- Abiding by professional and scientific ethics.

Strategic goals of Egyptian HE branching from these previous goals are; developing comprehensive and sustainable resource; utilizing scientific research and developing capacities; maximizing the role of HEIs as cultural and educational centers; developing education system and bylaws to allow for sustainable and life-long learning; comprehensive administrative reform of HEIs and integration of principles of total quality and sustainable development. These strategic goals of Egyptian HE emphasize having a national system of QA and a system for accrediting HEIs.

\subsection{Egyptian QA and accreditation policy}

As governments in most parts of the world have considered their agenda for HE over the last few decades, issues of QA and quality enhancement have been a major focus of attention. Many governments have decided that traditional academic controls are inadequate to today's challenges, and more explicit assurance about quality is needed.

Most national systems are based on the "four stage model" of external evaluation, (a) a coordinating agency, (b) submission of a selfevaluation report, (c) a peer visit and (d) a public report, and there are many variations within this general scheme [13].

The history of establishing an internal QA and accreditation system of Egyptian HEIs goes back to February 2000; a strategic plan was presented at the National Conference for Higher Education under the auspices of the President of Egypt. The strategy was built within the government's vision for HE in the $21^{\text {st }}$ century, and aimed at achieving the strategic objectives of reform. During this phase grants were provided by various organizations in order to cover the costs of preparing the reform strategy for HE [14].

In addition to these previous grants, a loan agreement was signed between the International Bank for Reconstruction and Development (IBRD) (lender) and the MOHE the (borrower) dated April 23, 2002. The IBRD agreed to lend the MOHE an amount equal to fifty million dollars. According to this loan agreement, the Egyptian HE strategic plan was titled "Higher Education Enhancement Project (HEEP)". One of the most important objectives of the HEEP was to improve the quality and relevance of HE, so that graduates will have the knowledge and skills demanded by Egypt's developing and globalizing economy [15].

In realizing HEEP's objectives, the HEEP has been translated into twenty-five distinct projects addressing diverse areas of HE reform. These projects are being implemented in three phases until 2017, and these correspond to the government's five year plans. Twelve of the twenty-five projects have been bundled into six components, hereinafter called projects too, and were given priority to be funded and implemented. The Quality Assurance and Accreditation Project (QAAP) is one of these main projects (Figure 1); these projects are:

- Higher Education Enhancement Project Fund (HEEPF)

- Faculty-Leadership Development Project (FLDP)

- Information and Communication Technology (ICTP)

- Faculties of Education Enhancement Project (FOEP)

- Egyptian Technical Colleges Project (ETCP)

- Quality Assurance and Accreditation Project (QAAP)

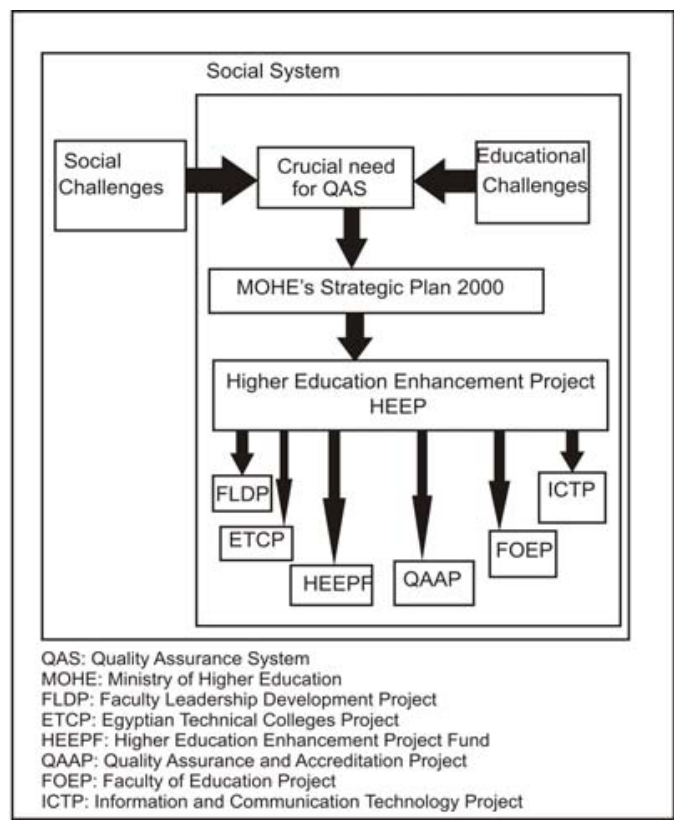

Figure 1. QAAP emergence as one of HEEP

Simply, we can say that the history of QA and the accreditation system in Egypt, till present, is divided into two main phases; the first phase is the QAAP, till June 2009, the second phase of this history, the present case, is the Program of Continuous Improvement and Qualifying for Accreditation (PCIQA).

5.2.1 Phase 1: the Quality Assurance and Accreditation Project (QAAP). The QAAP's main mission is to assure quality, on-going improvement and increasingly effective performance of HEIs to gain the confidence of the community in the capabilities and efficiency of their graduates at the national and international levels, by means of supporting public universities to become accredited. 
The QAAP seeks to realize its mission through essential steps which are considered the beginning of establishing internal QA and accreditation systems as follows;

- Establishing the National Authority of Quality Assurance and Accreditation in Education (NAQAAE);

The NAQAAE was established by the preliminary law, after QAAP participation in both people's Assembly and Shura Council. The Presidential Decree was issued for its establishment in June 2006. The QAAP provided the NAQAAE with its outputs which include the following; 1- The standards for institutional accreditation of academic institutions. 2- The National Academic Reference Standards (NARS) for the educational programs. 3Database of peer reviewers, field visits team leaders, and technical experts and administrators trained for five years in the domain of educational quality.

- Disseminating the culture of quality in the academic community and among all beneficiaries of educational services; The QAAP realizes this objective through the following;

- training more than 4,000 staff members in coordination with the Quality Assurance Centers in Egyptian universities, to consolidate the concepts of quality in the academic community and among university leaders;

- training more than 700 faculty members to be peer reviewers and team leaders in the field visits to various academic institutions;

- training all managers of the 17 quality centers to identify their roles with the faculties in training on standards and the concepts of quality, and how to conduct self-assessment and write annual reports;

- training more than 500 faculty members on how to draft the university strategic plans for QA, and how to design action plans for development and continuous improvement;

- conducting a series of awareness- raising campaigns for more than 900 faculty members on how to develop and use NARS as a reference for educational programs;

- holding meetings and discussions with different audio and visual media and newspapers to introduce the project, and holding seminars on educational QA and its relevance to society;

- $\quad$ holding The First National Conference for Quality Assurance and Accreditation in 2007, attended by more than 1,000 participants from the academic community and beneficiaries of educational services;

- directors and members of the QAAP's committees have participated in regional and international conferences in Europe, United States of America, New Zealand and Canada to find the best experiences in QA, and compare them with the Egyptian system for QA and accreditation; representing Egypt in the International Network for Quality Assurance and Accreditation in Higher Education (INQAAHE).

- Establishing Quality Assurance Centers in Egyptian public universities

The QAAP established 17 Quality Assurance Centers in public universities, some of them have been included in the administrative and financial organizational structure of the universities, and most of their directors have become members of the university council. The university centers support the Quality Assurance Centers in the public universities to produce their annual reports; they also participate in preparing faculties and providing them with necessary technical assistance towards accreditation and on-going improvement of their programs. The QAAP trained all employees and directors of the Quality Assurance Centers on the concepts and standards of QA and accreditation.

- Developing strategic plans for QA in the public universities;

The QAAP completed the strategic plans for 14 Egyptian public universities, identifying strengths and points that need improvement. These strategic plans of Egyptian universities have been evaluated by international experts, and a report has been made for each university. Each public university developed its operational plans and set its priorities to support the academic institutions to apply for accreditation from the NAQAAE, according to a realistic and clearly prioritized timeframe.

- Developing the National Academic Reference Standards (NARS);

The QAAP finalized NARS for 10 sectors in the light of international standards for educational programs, job market needs and competitiveness, as well as national needs. These sectors are nursing, agriculture, engineering, veterinary medicine, basic sciences, pharmacy, home economics, medicine, arts, and physical education. Moreover, the QAAP reviewed of current educational programs by related sector committees, and examined the possibility of applying NARS on the programs, so that the academic institutions would follow the standards in their educational programs.

- Establishing an internal quality assurance system in public universities;

The QAAP offered competitive projects to all faculties of public universities to apply for funds to establish an internal quality assurance system. 150 faculties obtained these projects throughout three different cycles held during the life of the project. Moreover, 15 faculties of education were funded, to 
establish internal quality assurance systems through the Faculty of Education Project (FOEP).

Through the QAAP monitoring teams, the national committee periodically monitored and reported on the progress of all the projects (150 projects +15 education projects) in establishing their internal quality assurance systems. The monitoring reports were sent to the faculties' deans and universities' presidents. 150 academic institutions were able to establish internal quality assurance systems, and prepare the required document, which include the first annual report.

The monitoring committee has developed the overall framework for the evaluation of the internal quality assurance systems in all academic institutions, which contains the following items; athe academic standards of the program, including: the targeted learning outcomes, criteria, student assessment, and student achievement; b - quality of learning opportunities, which include; teaching and learning, student support and learning resources; c research and scholarly activities; $\mathrm{d}$ - community and environmental services; e - the effectiveness of quality management and enhancement.

The QAAP conducted 120 Development Engagement (DE) visits in 16 public universities during the improvement phase, in collaboration with peer reviewers, to give the academic institutions an opportunity to test, develop, and improve their internal quality assurance systems, and have a DE report containing the points of strength and areas requiring further improvement to be taken into account in future improvement plans to achieve accreditation by NAQAAE.

The monitoring committee conducted follow-up visits to the faculties which had previously received DE visits and were ready for a second visit, to evaluate progress in applying the QA system and the efficiency of their action plans.

By June 2009, Egypt finished the first phase of QA and accreditation policy and the started the PCIQA, as second phase.

\subsubsection{Phase 2: Program of Continuous} Improvement and Qualifying for Accreditation (PCIQA) in HEIs. The PCIQA mainly consists of 7 projects; the Quality Assurance and Accreditation Project 2 (QAAP2); the Continuous Improvement and Qualification for Accreditation Project (CIQAP); the Development Academic Programs for Accreditation Project (DAPAP); Higher Education Institutions' Labs Accreditation Project (HLAP); Development of Student Assessment Systems Project (DSASP); Infrastructural Quality Related Projects (IQRP) ; and Monitoring and Evaluation of New Programs Project (MENPP).

The PCIQA aims at serving the greatest number of faculties by a developmental mechanism in Egyptian universities, and its means of fulfilling this is by making full use of available funds and guaranteeing their fair distribution. This program also aims at upgrading the potential of faculties and universities to benefit from the allocated budget, and finding alternative venues for developmental projects. Therefore, as a means of supporting the HEIs in developing a working system, as well as upgrading its institutional capabilities to comply with the QA standards and accreditation, the PCIQA is funding competitive projects, the above-mentioned projects.

The PCIQA follows procedures in evaluating the submitted projects, which includes, classifying the submitted projects from national HEIs into groups according to specialty and size; allocating evaluators to check the eligibility of the proposed projects; the evaluators committee will submit a technical report; analyzing the results and reaching initial indicators based on needs analyses reports and funding; and signing contracts with the successful projects within four weeks of result announcements.

The PCIQA depends on several criteria in evaluating the proposed projects from the Egyptian universities, which consist of;

- Academic Excellence, to what extent will the proposed project contribute to applying higher level of learning, matching the international level.

- Technical quality; this criterion is related to the formatting of the proposed presentation.

- Fulfilling accreditation requirements; did the proposed project address steps and outcomes that would fulfill either current or future accreditation, whether on the local or international accreditation level?

- Efficiency; will the project assist the faculty/institute to use its resources better?

- Sustainability; what is the nature and extent of resources made for the proposed project by faculty/institute?

- Cooperation; is the project multi disciplinary? Is there any cooperation with other institutions? Is there any sort of international cooperation?

- Creativity; is the project new in its idea or structure or both? This is also related to the effective impact on other institutions.

For continuous development of Egyptian QA policy, and depending on these criteria, the PCIQA decides which projects will be funded for more development to the internal QA and accreditation of the owner, the faculty/institute.

\section{QA and accreditation life cycle of Egyptian HE}

The Egyptian HEIs have the responsibility for maintaining and continually improving the academic 
standards of their programmes that comply with national standards, and the quality of the learning opportunities provided. The QA and accreditation life cycle is divided into two phases; the agenda and formulation phase, and the implementation phase.

\subsection{Agenda-setting and formulation phase of QA and accreditation system}

This phase will be shown through presenting its main features:

- The National Quality Assurance and Accreditation Committee (NQAAC), formed in October 2004, is composed of members representing state public universities, private universities, SCU, and other experts in the QA field [16]. Its main goals are; create awareness of the culture of QA among HEIs and community, and prepare HEIs for QA and the accreditation process based on international best practices.

- The QAAP adopted several activities in order to achieve its goals, such as; conducting training workshops for academic staff, conducting seminars and symposia to raise awareness and create a quality culture among the academic community, organizing site visits to follow up the progress achieved, and establishing a support and monitoring system to audit the projects it provided.

- For sustainability of the QA and accreditation system, the QAAP established three main entities to become parts of the organizational structure of each HEI, namely; University Project Management Unit (UPMU), Faculty/Leadership Development Center (FLDC), and Quality Assurance and Accreditation Center (QAAC). The prime concern of these entities would be to coordinate their activities to support the top administration of the university/HEIs to implement the main interrelated functions of the reform plans adopted by their university.

- QAAP and SCU shared in setting National Academic Reference Standards (NARS) which were drawn from the best practices internationally, which reflect the range and standards of academic activities associated with HEIs nationally, regionally and internationally [17].

- Establishment of NAQAAE with the main mission, to assure the quality of Egyptian education institutions, continuous improvement and efficient performance, consistent with their mission statements and objectives, as well as ensuring public confidence through independent, impartial and transparent operations.

The NAQAAE is considered to be an independent national QA and accreditation mechanism reporting directly to the Prime Minister. According to its establishment law, in 2006, the authority is responsible for evaluating more than 50,000 educational institutions to be accredited within 5 years [18].
According to Law No. 82 for the year 2006 regarding the establishment of the NAQAAE, the authority aims at assuring the quality of education and its ongoing development through; disseminating quality culture; coordination with educational institutions to ensure reaching an integrated system of standards, development of comparison rules and performance assessment mechanisms, which are guided by international standards and at the same time in a way that fits with Egypt's identity; supporting the capacities of educational institutions so that they can undertake self-evaluation; emphasizing confidence in the quality of the outcomes of the educational process at the local, national and international level, and in a way that fits with the Egyptian identity; and comprehensive evaluation of educational institutions and their programs against the benchmarks and approved standards for each educational stage and each type of educational institution.

In this section we show the main features of the QA and accreditation system, which can be summarized as: the NAQAAE is the responsible authority for the accreditation process, as a representative to MOHE, and the NARS is the main source of standards for establishing internal QA and accreditation systems in Egyptian universities, and the accreditation process which is followed by NAQAAE.

\subsection{Implementation phase}

In short, the implementation phase of the QA and accreditation life cycle is the accreditation process.

Accreditation processes and agencies responsible for implementing them must be evaluated to ensure that the accreditation mechanisms are functioning effectively, efficiently and equitably. Accreditation mechanisms can be formed by a governmental agency, an autonomous non-governmental agency created by HEIs, or by professionals in the HE, and business or industry sectors.

In Egypt, accreditation for HEIs is the recognition accorded by NAQAAE to an institution, which can demonstrate that its programs meet acceptable standards according to the criteria or standards published by the national authority. Moreover, MOHE wishes to encourage institutions to apply for and achieve accredited status as soon as permitted in Egypt, since 2007.

Accreditation scope covers three main academic activities of all institutions; educational programs, research and other scholarly activity, and community involvement. There are three types of accreditation schemes adopted by NAQAAE:

- The institutional accreditation (faculties)

- Program accreditation (e-learning, engineering, etc)

- University accreditation 
This stage of implementation, the accreditation phase, consists of identified steps [17] [19].

- The self-evaluation step; the QA \& accreditation unit for faculties, and QA \& accreditation centers for universities, prepare internal annual self-evaluation reports and the strategic 5-year review reports. The institution also may, if it wishes, write an additional brief selfevaluation report in preparing for the peer review.

- The peer-review step; both the national authority and the institution consider the timing of a site visit and the size and composition of the peer review team needed.

- Judgements and accreditation report; using the criteria for accreditation, the reviewers judge the extent to which the institution has met the criteria, and if not, what further improvements are required.

An institution which needs further improvements before it is accredited, is responsible for preparing its action plan for further improvements. Then the authority will arrange further review activity.

- The arrangements for re-accreditation; the authority will invite an accredited institution to prepare for re-accreditation at an interval normally of five years.

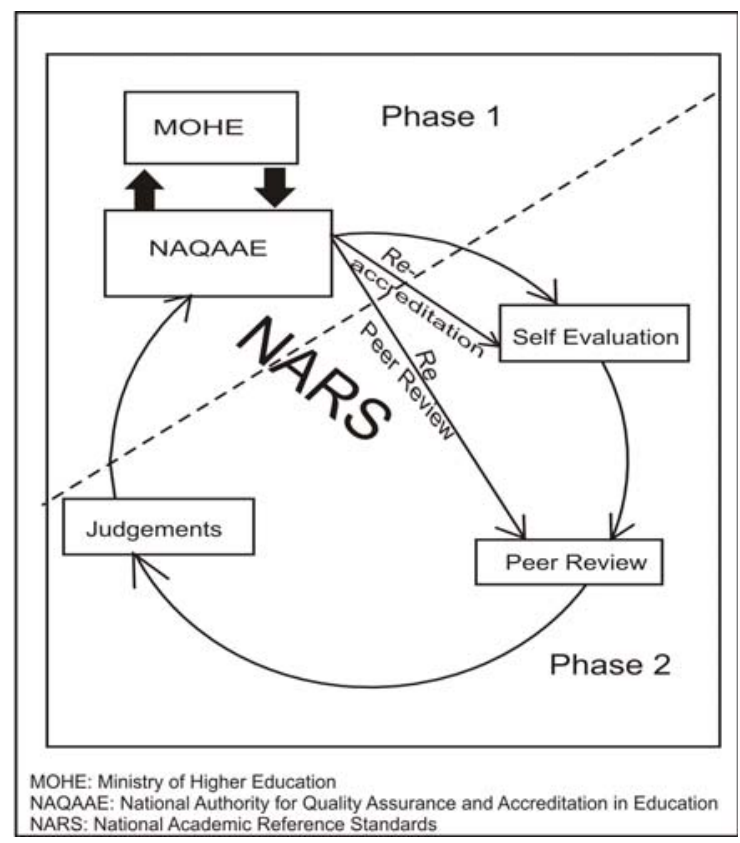

Figure 2.Egyptian QA and accreditation life cycle

Figure 2 simply shows the QA and accreditation life cycle, which consists of two main phases. The first is the agenda setting and formulation stage, and the second is the implementation or accreditation phase.

\section{Discussion}

From the policy transfer perspective, and based on globalization effects on HE not only in developed countries but also in developing countries as well, we suppose that there are four kinds/channels of QA policy transfer in Egypt, as shown in Figure 3.

Depending on our suggested Theoretical Model, we suppose that each country acquires policy/knowledge of QA of HE through four kinds or channels of transferring QA policy/knowledge; global, regional, international, and national transfer. We also suppose, in our discussion, that N1 is Egypt. . We classified these channels according to two criteria, first, the range of connection, and second, the degree of connection between the NAQAAE, (as the national partner) and others as follows.

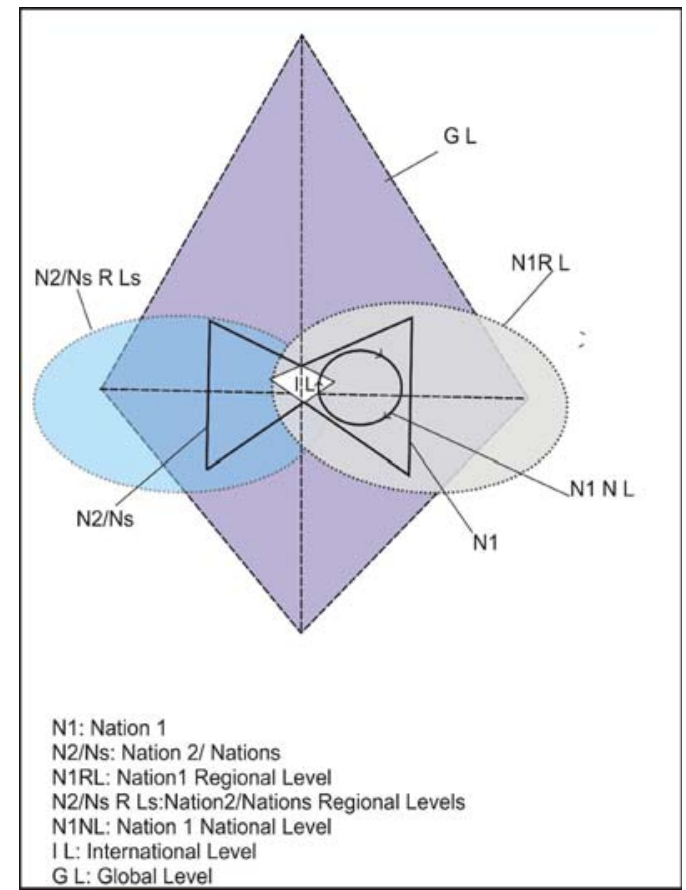

Figure 3. a theoretical model of kinds/channels of QA and accreditation policy transfer

Global transfer, (GL); in this kind, or channel, of transfer, Egypt depends on the link between its national authority NAQAAE and the global networks of QA and accreditation policy, such as the Quality Assurance Agency (QAA) [20].

The QAA's mission is to promote public confidence that quality of provision and standards of awards in HE are being safeguarded and enhanced through:

- Working with HEIs to promote and support continuous improvement in the quality and standards of provision;

- Working with HEIs to develop and manage the qualifications framework; 
- Providing clear and accurate information to students, employers and others about the quality and standards of HE provision;

- Advising on the grant of awarding degrees and university title;

- Facilitating the development of benchmark information to guide subject standards;

- Promulgating codes of practice and examples of good practice;

- Operating programmes of review of performance at institutional and program levels.

Depending on its above-mentioned objectives, the QAA has launched global projects for QA policy, such as Erasmus Mundus program, which is a worldwide extension of the Erasmus program, aimed at increasing academic cooperation between various countries, and cooperation between the institutions of the European Union (EU) and third countries.

The Erasmus Mundus $\Pi(2009-2013)$ aims to enhance quality and development of HEIs, improve career prospects of students, and promote intercultural understanding between the partner countries. Moreover, besides the recent Erasmus Mundus Project in Egypt, Flow By Flow EU-Egypt Bridge Building (FFEEBB) aims to enhance academic cooperation between European and Egyptian universities by bringing together students and staff, as well as young and senior researchers for forming multidisciplinary teams and sharing of best practices between participating staff, in the field of university governance, and the implementation of the Bologna Process in the QA field.

This action will have a long impact upon the harmonization of HE systems in Egypt and the EU, thus decreasing the gaps existing between the institutions of both sides, and contributing to the recognition of the degrees delivered in Egyptian HEIs at the global level. Hence, the FFEEBB project can be viewed as a very important step towards the creation of a Euro-Mediterranean HE area, aiming, along the lines of the Barcelona Declaration, at building stronger ties of cooperation between European universities and universities in Egypt.

Another very famous example of global cooperation in the QA field is the International Network for Quality Assurance Agencies in Higher Education (INQAAHE), and Egypt has membership in this network, which is considered global means for transferring QA policies between its members.

The main purpose of this network is to collect and disseminate information on current and developing theory and practice in the assessment, improvement and maintenance of quality in HE. Therefore, the network seeks to; promote good practices in the maintenance and improvement of quality in HE; facilitate research into the practice of quality management in HE and its effectiveness; be able to provide advice and expertise to assist in the development of new QA agencies; assist members in determining the standards of institutions operating across national borders; permit better- informed international recognition of qualifications; and to enable members to be alert to dubious accrediting practices and organizations. Based on this aim, the INQAAHE helps Egypt in establishing the internal QA and accreditation system.

Regional transfer, (N1RL/N2/NsRLs); this kind of transfer includes contact between Egypt and other countries in the Middle East or the Islamic World in the QA field of HE such as, joining as a member in the Arab Network for Quality Assurance in Higher Education (ANQAHE), exchanging information, and dissemination of best practices in QA and so on.

The ANQAHE is a regional network that operates as an independent, non-profit nongovernmental organization, with many goals; to support and enhance QA organizations in the Arabic region; to develop capable human resources and establish a mechanism of cooperation in the field of $\mathrm{QA}$ in $\mathrm{HE}$ in the Arabic region, and to exchange information on QA in HE between many Arab region countries, such as; Egypt, Jordan, Saudi Arabia, Sudan, and others.

Through these kinds of interactions between Arab countries through ANQAHE as a channel, the exchange of QA policies and practices became more effective.

International transfer, (N1NL/N2/Ns); the clearest feature of international transfer is the direct link between Egypt and other countries in the QA field of $\mathrm{HE}$, for example through American and British aid in developing NARS, QA and accreditation agenda-setting and formulation, through supporting their consultants, experiences with NAQAAE [17], or through launching famous international projects in Egypt through foreign aid, such as the Trans-European Mobility Scheme for University Studies (TEMPUS) program, which was launched in Egypt through National TEMPUS Office in Egypt (NTO).

Since 2002, TEMPUS has played an important role in Egypt, with most Egyptian universities participating in a total of 64 TEMPUS projects. TEMPUS has a very great impact on the Egyptian HE system through its overall objective, which emphasizes contribution in an area of cooperation in the field of HE involving the European Union and partner countries in the surrounding geographic area and Central Asia. In particular, its specific objectives related to the QA area are;

- To promote the reform and modernization of $\mathrm{HE}$ in the partner countries;

- To enhance the quality and relevance of HE in the partner countries;

- To build up the capacity of HEIs in the partner countries and the EU, especially their capacity for international cooperation 
and for a permanent modernization process, and to assist them in opening themselves up to society at large;

- To enhance networking among HEIs and research institutions in both the partner and EU countries.

As a result of these objectives, one of the main elements of impact of TEMPUS in Egypt is the introduction of quality education through partnership with EU member states in different disciplines This mechanism was one of the most demanded in Egypt, which shows the interest of Egyptian academic staff in retaining and building bridges for mutual cooperation in the QA experience field.

Here we emphasize TEMPUS's role in launching a program for promoting the internal Egyptian QA system in many Egyptian universities.

National transfer, (N1NL); we suggest that this kind of knowledge/policy transfer concerns the outcome of the implementation/accreditation phase, and this outcome knowledge is considered in the highlighted guidelines for evaluating recent QA policy, and looking for more modifications in QA policy to match Egyptian cultural circumstances.

These outcomes, depending on the circulation nature of both QA and accreditation processes, again will become the inputs for further QA and accreditation processes next, and so on. So, we see that when inputs match the country's, Egypt's, national circumstances, (educational, political, economic, geographical, and so on) the more high level outputs will become.

\section{Conclusion}

There are, perhaps, four conclusions to be made from this review and analysis of Egyptian QA and accreditation policy in relation to policy transfer. First, QAAP is considered to be the real beginning of launching Egyptian QA and accreditation policy. At the same time, this project is considered to be the first phase, from the history side. The PCIQA is considered to be the second phase in establishing the internal QA and accreditation systems in all Egyptian HEIs. Second, both NAQAAE and NARS are main features of QA and accreditation policy. Third, the QA and accreditation life cycle mainly consists of two main phases; the agenda-setting and formulation of QA and accreditation policy phase, and the accreditation process as the implementation phase. The fourth and final conclusion is the presence of four different channels (the global, regional, international and national channels) for policy transfer, through which Egyptian QA and accreditation policy has acquired its current knowledge.

\section{Acknowledgements}

We would like to thank Ms. Mooradian, Global Communication Center, JAIST, for her English editing and helpful comments. We also would like to thank anonymous reviewers of this paper. The first author is highly grateful to the Egyptian Government (sponsor) for providing financial support.

\section{References}

[1] F. Maringe, "The Meaning of Globalization and Internationalization in HE: Findings from a World Survey," in F. Maringe and N. Foskett, (eds.) Globalization and Internationalization in Higher Education, Theoretical, Strategic, and Management Perspectives, Continuum, London, 2010.

[2] C. A. Torres \& R. A. Morrow "The State, Globalization, and Educational Policy", in N. C. Burbules \& C. A. Torres (eds.) Globalization and Education. Critical Perspectives, Routledge University Press, London, 2000, p. 44.

[3] P. Porter \& L. Vidovich, "Globalization and Higher Education Policy", Educational Theory, 50-4, WileyBlackwell, 2000, pp. 449- 465.

[4] M. Segers, and F. Dochy, "Quality Assurance in Higher Education: Theoretical Considerations and Empirical Evidence", Studies in Educational Evaluation, 22-2, Elsevier, 1996, p. 119.

[5] J. Parri, "Quality in Higher Education", VADYBA Management, 2-11, 2006, pp. 107-111.

[6] M. Frazer "Quality Assurance in Higher Education," in A. Craft, Eds. Quality Assurance in Higher Education, Proceedings of an International Conference, Routledge, London, 1992.

[7] D. W. Dolowitz, and D. Marsh, "Learning from Abroad: the Role of Policy Transfer in Contemporary Policy Making," Governance, 13-1, Wiley-Blackwell 2000, pp. 5-24.

[8] D. W. Dolowitz, "British Employment Policy in the 1980s: Learning from the American Experience," Governance, 10-1, Wiley-Blackwell, 1997, pp. 23-42.

[9] D. W. Dolowitz, and D. Marsh, "Who Learns from Whom: A Review of the Policy Transfer Literature", Political Studies, 44-2, Wiley-Blackwell, 1996, pp. 343357.

[10] P. T. Cheung \& C. B. Tsui, "Quality Assurance for All”, Quality in Higher Education, 16-2, Routledge, 2010, pp. 169-175.

[11] F. Hassan 'Science Education in Egypt and other Arab Countries in Africa and West Asia'; 
http://www.frontiersjournal.com/issues/vol3vol3-

11_Hassan.htm (2 October 2009).

[12] M. H. El-Meligi, "Egypt," in W. Wickremasinghe, (ed) Handbook of World Education, A Comparative Guide to Higher Education Systems of the World, American Collegiate Service, Houston, 1991.

[13] F. A. Van Vught \& D. F. Westerheijden "Towards a General Model of Quality Assessment in Higher Education", Higher Education, 28, Springer, 1994, pp. 355-371.

[14] Project Management Unit (PMU) 'Historical Background on Phases of Developing Higher Education, Enhancing over the Past Twenty Years 1989-2009'; http://www.heep.edu.eg/about-heep.htm $\quad(11$ October 2009).

[15] World Bank 'Loan Agreement HEEP between Arab Republic of Egypt and IBRD'; http://wwwwds.worldbank.org/external/default/WDSContentServer/W DSP/MNA/2004/12/15/FCE435098A5973D985256F0300 12FF27/1_0/Rendered/PDF/FCE435098A5973D985256F0 30012FF27.pdf (11 November 2009).

[16] Quality Assurance and Accreditation Project (QAAP) (2005) 'Operational Manual Including Application Form'; http://siteresources.worldbank.org/EDUCATION/Resource s/3314_a-iqs_operation-manual.pdf (19 November 2009).

[17] The National Quality Assurance and Accreditation Committee in Collaboration with British Consultants in Higher Education (2004) 'The Quality Assurance and Accreditation Handbook for Higher Education in Egypt'; http://siteresources.worldbank.org/EDUCATION/Resource s/41_handbook-qaa-en.pdf (2 June 2009).

[18] The National Authority of Quality Assurance and Accreditation in Education (NAQAAE); http://www.heep2.edu.eg/qaap_First\%20Phase/public.htm \#0 (10 January 2011).

[19] International Project Management Office 'Selfassessment Guide for Egyptian Higher Education Institutions in Quality and Accreditation Issues'; $\mathrm{http} / / / \mathrm{www}$.ua.es/en/internacional/internacionalizacion/exp ress/download/EXPRESS_guide.pdf (23 July 2009).

[20] The Quality Assurance Agency for Higher Education (QAA); http://www.qaa.ac.uk/ (2 December 2010). 